\title{
Diagnostic Reliability of Architect Anti-HCV Tests and Diagnostic Cost of False Positivity; A Single Center Study in Turkey.
}

\author{
Sinem Akkaya Isik ${ }^{1}$, Ersin Tural ${ }^{2}$, ERCAN YENILMEZ², RIZA AYTAÇ ÇETINKAYA ${ }^{1}$ \\ Orhan Baylan ${ }^{2}$, Levent Gorenek ${ }^{2}$, and Sukran Kose ${ }^{3}$ \\ ${ }^{1}$ Affiliation not available \\ ${ }^{2}$ Sultan Abdülhamid Han Training and Research Hospital \\ ${ }^{3}$ Ministry of Health Tepecik Hospital, Infectious Diseases Clinic
}

March 20, 2021

\begin{abstract}
Background:Although the sensitivity of third generation anti-HCV CIA tests is high, false positivity rates, especially in populations with low HCV infection endemicity, are still high. Objectives:We aimed to determine the S/Co cut-off value of anti-HCV in the diagnosis of real positive patients based on the CIA test kit absorbance routinely used in our laboratory and to reveal the potential cost effectiveness of confirmatory tests for false positive samples. Methods:All anti-HCV CIA test results which were performed in the microbiology laboratory of our hospital between 2016-2019 were retrospectively screened and S/Co values of the patients were recorded. Among these, the results that were confirmed with HCV-RNA real-time PCR test were included. Patients who were previously diagnosed and treated were excluded. Results:A total of 257 patients, who were tested for HCV-RNA after reactive anti-HCV test results, were included in the study. Of the cases, 84(32.68\%) had positive HCVRNA. According to the ROC analysis, the optimal S/Co value was 8.58 with the sensitivity and specificity values $95.24 \%$ and $85.55 \%$, respectively. According to this $8.58 \mathrm{~S} / \mathrm{Co}$ value, anti-HCV test was reactive in 105 cases and $80(76.2 \%)$ of these cases had active $\mathrm{HCV}$ infection. In order to prevent the false-negativity, the additional cost of using 1.0S/Co value to our institution was 4114.64USD, meaning that we spent 1028.66USD to diagnose per true-case of active HCV infection when using 1.0S/Co value. In our institution, approximately 6.25 working hours are spent to finalize the HCV-RNA PCR test. The hours spent for S/Co of 1.0 and 8.58 were 1606.25 and 658.25 , respectively. Conclusions:False positive anti-HCV results are an economic burden on health economics of countries. At least, different $\mathrm{S} /$ Co values might be used in accordance with the purpose of the screening (like blood donors or pre-operative screening) and prevalence of HCV infection in different laboratories and different populations.
\end{abstract}

\section{Introduction}

The hepatitis C virus (HCV) was first described in 1989, and its prevalence has increased gradually over the years. According to the World Health Organization (WHO), $1 \%$ of the world's population were infected with HCV in 2015. The highest prevalence is observed in Eastern Mediterranean and European countries $(2.3 \%, 1.5 \%$ respectively). In other parts of the world, the prevalence varies between $0.5 \%$ and $1.0 \%$ (1). Despite being located in the Eastern Mediterranean Region, the HCV prevalence is 0.7\% in Turkey (2).

The enzyme immunoassay (EIA) or chemiluminescence immunoassay (CIA) methods, that detect specific antibodies, are used to screen for hepatitis $\mathrm{C}$ virus infection. Considering the development of EIA, only one HCV recombinant antigen derivative was used in first-generation tests. First-generation anti-HCV 
EIA tests have low sensitivity in high-prevalence populations, but they can lead to false positives in lowprevalence populations. Therefore, the sensitivity and specificity of second-generation anti-HCV EIA tests were increased by adding two protein derivatives to first-generation anti-HCV EIA tests. Third-generation anti-HCV EIA assays, which are commonly used today, are developed by adding a fourth protein derivative to second-generation assays. Although the sensitivity of third-generation anti-HCV EIA tests is high, false positivity is still observed (3). Consequently, reactive anti-HCV test reagents should be confirmed by a recombinant immunoblot assay (RIBA) or nucleic acid amplification test (NAT) $(4,5)$.

The United States Centers for Disease Control and Prevention (CDC) have reported that anti-HCV signal sample / cutoff (S / Co) values in EIA / CIA may be used to estimate the likely outcome before validation methods (5).

During hepatitis $\mathrm{C}$ screening, a reactive/positive result may be reported by using different $\mathrm{S} / \mathrm{Co}$ values based on different risk groups (6). However, in Turkey, only one S/Co value specified in the Anti-HCV kit manual is being used. In this study, individuals without risk factors such as preoperative patients, blood donors and marriage or job applicants were examined. The purpose of our study was to determine the S/Co cutoff value in true positive patients by taking the absorbance of the CIA test kit that is routinely used at our laboratory as a basis and to investigate the potential cost-effectiveness of applying reflex test for false positive samples based on this value. Another purpose of this study was to facilitate the access of more people to the test by reducing diagnostic costs in countries with limited economies like Middle Eastern and North African countries by using this determined value.

\section{Materials and Methods}

This diagnostic accuracy study was conducted at the Department of Infectious Diseases and Clinical Microbiology of the Health Sciences University Sultan 2. Abdulhamid Han Research and Training Hospital.

\section{Patient groups}

In this study, for screening purposes without risk factors, the results of 42606 anti-HCV CIA tests which were performed in the microbiology laboratory of our hospital between 1 January 2016 and 1 January 2019 were retrospectively screened, and the S / Co values of the patients were recorded. Patients who were previously diagnosed and treated with interferon or direct acting agents were excluded. Among the remaining, the 257 results that were confirmed with HCV-RNA (NAT) tests were included. Additionally, only one laboratory test result of each patient was included in the study to prevent bias. For this purpose, if the anti-HCV EIA test was repeated in patients with positive HCV-RNA, the lowest S / Co value was recorded. The highest anti-HCV S / Co value among the repeated tests of the patients with negative HCV-RNA was also included.

\section{Anti-HCV Assay}

The anti-HCV test was performed by using the chemiluminescence immunoassay (CIA) method on the serum samples of the patients by using Architect i2000SR (Abbott Diagnostics@, Wiesbaden, Germany). $\mathrm{HCV}$ antibody levels were determined by the ratio of the signal (signal sample=S) measured by the device to the cutoff value of the test $(\mathrm{Cutoff}=\mathrm{Co})(\mathrm{S} / \mathrm{Co}=$ cutoff index $[\mathrm{COI}])$. Based on the instructions of the kit's manual, those with values of $0.99<\mathrm{S} / \mathrm{Co}$ were accepted as reactive.

\section{HCV-RNA measurement}

HCV-RNA levels (viral loads) were determined by the real-time polymerase chain reaction (PCR) method. HCV-RNA isolation was performed using a Magnesia (B) 2448 Nucleic Acid Extraction \& PCR Setup Robot and Magnesia@ 2448 Viral DNA / RNA Extraction Kit (Anatolia Geneworks, Turkey). After isolation, the viral loads of the serum samples were determined by Applied Biosystems (ABI) 7500 Real-Time PCR using a Bosphore HCV Quantification Kit (Anatolia Geneworks, Turkey). The dynamic range of the test was 25 $\mathrm{IU} / \mathrm{mL}$, and the linear range was $25 \mathrm{IU} / \mathrm{mL}$ and $1 \times 10^{8} \mathrm{IU} / \mathrm{mL}$.

\section{Laboratory-clinical test algorithm}


In our hospital, the CDC 2013 manual is used as the laboratory-clinical approach (7). According to this manual,

- Non-reactive anti-HCV results with CIA are reported as non-reactive, and no additional testing is performed.

- Reactive anti-HCV results are considered to be compatible with active HCV infection or previous HCV infection or false positivity. The HCV-RNA (NAT) test is used to distinguish these three conditions. Cases with positive HCV-RNA tests are considered as active HCV infection and treated under followup.

- Most cases where anti-HCV is reactive, and HCV-RNA cannot be detected are considered as no current HCV infection, and no further procedures are required.

In our hospital, only NAT is used as a reflex test, and RIBA test cannot be applied.

\section{Statistical analyses and economic evaluation}

The statistical analyses were conducted by SPSS 15.0 and web-based computation (Vassarstat: website for statistical computation)/medcalc trial version. Mean and standard deviation values were used as descriptive statistics for the quantitative variables. Diagnostic accuracy was defined for the actual Co value estimated by receiver operating characteristics (ROC) analysis. A confidence interval of 0.95 was used for statistical significance. The mean and marginal costs were used for economic evaluation. Cost for unit was estimated from a provider perspective. Reimbursement and currency rates published by local authorities (Social Security Institution and Central Bank) on the dates of 4 and 1 February 2018 were utilized. Sensitivity analysis was not conducted for the comparison of cost impacts.

\section{Ethics committee approval}

This study was carried out with the approval of the Hamidiye Non-Invasive Studies Ethics Committee of the University of Health Sciences (Date: 29.03.2019, number: 19/41).

\section{Results}

A total of 42606 anti-HCV tests were performed in our hospital within the study period. After excluding the duplicating anti-HCV test results of the same patients, 428 of the remaining 36019 tests were found to be reactive. In 159 of these cases, although the anti-HCV test result was reactive, a confirmation test was not carried-out. Additionally, 12 patients had already been diagnosed with chronic hepatitis $\mathrm{C}$ or were still receiving treatment for HCV infection. Finally, we had 257 naive cases among which anti-HCV tests were reactive, and HCV-RNA PCR confirmation tests were performed. According to the confirmation test results by NAT, HCV-RNA was not detected in $173(67.32 \%)$ of the 257 anti-HCV reactive serum samples. For 84 $(32.68 \%)$ cases with positive HCV-RNA, the test results were defined as active HCV infection (Figure 1).

We also performed ROC analysis to determine the anti-HCV Co value. According to the analysis, the optimal $\mathrm{S} /$ Co value was 8.58 with the sensitivity and specificity values of $95.24 \%$ and $85.55 \%$, respectively. The area under the ROC curve was 0.942 (95\% confidence interval, 0.913-0.971) (Figure 2, Table 1). According to this $\mathrm{S} / \mathrm{Co}$ value (8.58), the anti-HCV test was reactive in 105 cases, and $80(76.2 \%)$ of these cases had active $\mathrm{HCV}$ infection. However, when this S / Co value was applied, anti-HCV was non-reactive in four patients although they were diagnosed as active $\mathrm{HCV}$ infection. When these cases were examined, their anti-HCV $\mathrm{S} / \mathrm{Co}$ titers were found to be 1.82, 6.05, 6.98 and 7.39. The patient who had an anti-HCV S/Co value of 1.82 was 73 years old, had normal transaminases and had a low titer of HCV-RNA ( $80 \mathrm{IU} / \mathrm{mL}$ ). The subsequent follow-up revealed a spontaneous negative viral load with non-reactive anti-HCV, and the result was concluded as false positive HCV-RNA. When the other cases were examined, the transaminases were high, and they were concluded as active HCV infection.

According to the Health Application Communiqué published on 4 February 2018, in Turkey, the unit cost of an HCV-RNA PCR test was 27.07 USD (8). When the signal / cutoff value was evaluated as 1.0, the cost of the HCV-RNA PCR assay studied for 257 subjects with an anti-HCV CIA test reagent was 6956.99 
USD. However, if the S / Co value were determined as 8.58, the cost of 105 cases would be 2842.35 USD. Nevertheless, four cases with active HCV infection would be missing due to the increased S / Co value. In order to prevent false-negativity, the additional cost of using the S / Co value of 1.0 to our institution was 4114.64 USD, meaning that we spent 1028.66 USD for diagnosis per true-case of active HCV infection when using an S / Co value of 1.0 (Table 2a).

At our institution, approximately 6.25 working hours are spent to finalize an HCV-RNA PCR test. The hours spent were 1606.25 with S / Co 1.0, and the hours spent were 658.25 when the S / Co value was 8.58. Accordingly, the time spent for each case was 237.5 hours (Table $2 \mathrm{~b}$ ).

\section{Discussion}

Hepatitis $\mathrm{C}$ virus infection screening is performed by an anti-HCV test. HCV screening is required in many situations in Turkey such as pre-marriage or pre-operative screening, besides screening of blood donors and high-risk populations. In anti-HCV reactive cases, active infection is confirmed by an HCV-RNA PCR test $(5,7)$. The false positivity rate of a screening test increases as the prevalence of the disease decreases in the community. Since Turkey is among countries with low prevalence in terms of HCV infection, the false positivity rates of the test are high (2). This is an important cause of increase in medical costs and labor loss in Turkey.

In a letter to the Abbott laboratories in 2007 by the Centers for Disease Control and Prevention (CDC) including a study's results among low-prevalence and high-prevalence populations, the proportion of RIBApositivity was $97 \%$ among samples with a mean $\mathrm{S} /$ Co ratio of 5 . In this letter, it was suggested that no confirmation test should be performed at $<5 \mathrm{~S} /$ Co values in the laboratories running in vitro diagnostic anti-HCV tests, and positivity should be reported after confirmation testing at [?]5 S / Co values (9). When an [?]1 S / Co value was applied for positive anti-HCV results according to the user manual of the kit in our laboratory, the true positivity rate in our study was $32.68 \%$. However, when the S / Co value had been applied as [?]5 based on the CDC recommendation, 129 patients would have been found to have reactive anti-HCV test results, and $83(64.3 \%)$ of them would have had active HCV infection. One undiagnosed case was a 73-year-old patient with normal transaminases and a viral load below $100 \mathrm{IU} / \mathrm{mL}$. Additionally, HCV-RNA decreased to an undetectable level with non-reactive anti-HCV in that patient during follow-up.

According to the results of a study published in 2012 by Ecemis et al . which had a total of 387 patients for HCV-RNA PCR testing, 197 of whom were anti-HCV reactive, and 190 were non-reactive, the PCR tests resulted positive in 79 cases, while 308 cases had negative PCR results (10). In the study, when the reactivity threshold (S / Co) of anti-HCV was considered as 1, the sensitivity, specificity, positive predictive value (PPV) and negative predictive value (NPV) of the test were $94.9 \%, 60 \%, 38.1 \%$ and $97.9 \%$, respectively. Ecemis et al . found the optimal S / Co value as 5.06 in their ROC analysis, and the determined that the sensitivity and specificity of the test were $92.4 \%$ and $76.6 \%$, respectively (10). In our study, the optimal S / Co value was 8.58, and the sensitivity and specificity values for this value were $95.24 \%$ and $85.55 \%$, respectively. The $\mathrm{S} / \mathrm{Co}$, sensitivity and specificity values were all higher in our study. It was also found that HCV-RNA PCR was positive in four of the anti-HCV non-reactive cases $(4 / 190)$ when the ratio of the signal sample to the cutoff (S/Co) was applied as [?] 1. However, this unit of data contradicted the literature in Turkey since Turkey is a low endemic country for HCV infection. According to the data of the Turkish Red Crescent, the estimated HCV infection window period (anti-HCV non-reactive, NAT positive) risk ratios for blood donors tested for the first time were reported as 2.97, 4.37, 3.4 and 3.6 / million donations for 2015, 2016, 2017 and 2018, respectively (11). In comparison to this information, the HCV infection window period (anti-HCV non-reactive, NAT positive) risk ratio was very high in the study of Ecemis et al ., and the optimal cutoff value in the study was also lower than ours. The study could be conducted on high-risk populations including patients with hemodialysis or IV drug users. Since the criteria for inclusion of reactive and non-reactive cases in the study and the S / Co values of four false negative cases were not given in detail, we could not comment on the reason for the high rate.

Since NAT, RIBA or PCR have not been performed on the anti-HCV non-reactive samples at our institution 
in clinical practice, and our study was conducted retrospectively, we cannot comment on the positive and negative predictive values in our study, and our data cannot be compared to the data of the Turkish Red Crescent or Ecemis et al. This may be considered as one of the limitations of the study, and there is a need for prospective studies to reveal the rate of anti-HCV non-reactive but HCV-RNA positive patients.

In another study carried out in Turkey in 2016, HCV-RNA PCR tests were performed for confirmation in 658 anti-HCV reactive cases, and the optimal value was found to be $5.0 \mathrm{~S} /$ Co with the sensitivity and specificity values of respectively $95.6 \%$ and $52.7 \%$ by ROC analysis (12). The confirmation tests, just in the same way as our study, were performed only in the anti-HCV reactive cases in their study, and an HCV-RNA PCR test was not performed in the non-reactive cases.

In the study of Wu S. et al. in which four different antibody-screening tests (InTec, CHB, Wantai, Architect) were used, 336 of 22,626 clinical samples resulted as anti-HCV reactive (13). Among the anti-HCV reactive samples, 205 (61\%) were found to be positive when confirmed by HCV NAT, and the anti-HCV S / Co values in these samples were revealed to be high. More than $95 \%$ of the samples had S / Co values of $>8.00$ (InTec), 6.00 (KHB), 12.00 (Wantai) and 8.00 (Architect). Additionally, the optimal S/CO ratio was 5 for those with 95\% PPV when the Architect kits were analyzed separately for S / Co values of $<1,1-5$ and $>5$.

In a study published in Korea by Seo S. U. et al ., it was revealed that the most appropriate anti-HCV S/CO value was 10.9 by ROC curve analysis (sensitivity, $94.4 \%$; specificity, $97.3 \%$ ), and the area under the ROC curve was 0.989 (95\% CI, 0.981 to 0.998$)$ (14). In another study by Fletcher G. J. et al. , the sensitivity and specificity values for S / Co 6.28 were found to be $94 \%$ and $91.1 \%$, respectively (15). The area under the ROC curve was 0.9499 (95\% CI: 0.9273 to 0.9724 ). In our study, the optimal S / Co value was 8.58 (sensitivity, 95.24\%; specificity $85.55 \%$ ), and the area under the ROC curve was 0.942 (95\% CI: 0.913 to 0.971).

In the literature, there are not many studies about the optimal S / Co ratio in EIA tests used in HCV screening and the cost analysis of the confirmation tests and false positive results of anti-HCV tests. The only publication in this regard was the one by Garcia et al . which was a cost-effectiveness study of seven HCV test strategies performed in blood donors in a low-prevalence population (16). Three of the seven strategies were based on the HCV diagnosis-reporting guide in Mexico, and four were based on the CDC recommendations. In these strategies, RIBA and HCV-RNA NAT tests were used to determine antibody levels according to the $\mathrm{S} / \mathrm{Co}$ value and confirm true positive cases. In the CDC 1, 2 and 3 strategies, the $\mathrm{S} /$ Co values were [?]1, [?]1 and [?]8, respectively. RIBA and HCV-RNA NAT were performed together in different sequences (e.g., NAT first, then RIBA or vice versa). In the CDC 4 strategy, S / Co [?]1, only HCV-RNA NAT was performed. In the Mexico strategies, there were three different groups (M 1, M 2 and M 3), and three different antibody levels were determined for each group. These levels were very low (1[?]S $/$ Co $<4.5)$, low $(4.5[?] \mathrm{S} / \mathrm{Co}<20)$ and high $([?] 20)$, respectively. As with the CDC strategies, RIBA and HCV-RNA NAT were performed concurrently, but in different sequences. In their study, confirmation tests at very low S / Co levels were not performed in the Mexico 1 (M1) strategy. As a result, the M1 strategy was found to have the lowest cost when compared in accordance with the cost of true positivity per patient, and it was stated that this strategy had the lowest diagnostic power. The strategies M 2, M 3 or CDC 3 were revealed to be cost-effective, and their costs were 197, 185 and 195 USD, respectively. In our laboratory, a strategy similar to CDC 4 was applied, and the cost was 245 USD, while the cost of confirmation (PCR test only) was approximately 82 USD. If the S / Co value of 5 recommended by the CDC were applied, the cost would be 42 USD. However, the cost would be 35 USD when the S/Co value of 8.58 , which was revealed as the optimal value in the current study, was applied.

\section{Conclusion}

Low S / Co levels may cause false positive results in countries with a low prevalence of HCV infection like Turkey. The high rate of false positive anti-HCV test results causes psychological stress in patients, labor loss in health workers and additional burden on the health economics of countries. In [order to prevent this, we recommend classifying or increasing the $\mathrm{S} / \mathrm{Co}$ level in the screening procedure according to the risk 
population. At least different S / Co values might be used in accordance with the purpose of the screening (like blood donors or pre-operative screening) and the prevalence of HCV infection in different laboratories, different situations and different populations.

\section{References}

1. Progress report on HIV, viral hepatitis and sexually transmitted infections 2019. Accountability for the global health sector strategies, 2016-2021. Geneva: World Health Organization; 2019 (WHO/CDS/HIV/19.7). Licence: CC BY-NC-SA 3.0 IGO. [cited 2020 Jan Jul 9]. Available from: https://apps.who.int/iris/bitstream/handle/10665/324797/WHO-CDS-HIV-19.7-eng.pdf.

2. NHS Executive. Turkiye Viral Hepatit Onleme ve Kontrol Programi 2018-2023. Ankara: Department of Health; 2018.

3. Kim S, Kim JH, Yoon S, Park YH, Kim HS. Clinical performance evaluation of four automated chemiluminescence immunoassays for hepatitis C virus antibody detection. J Clin Microbiol. 2008 Dec;46(12):3919-23. doi: 10.1128/JCM.01603-08. Epub 2008 Oct 22. PMID: 18945839; PMCID: PMC2593301.

4. Kim B, Ahn HJ, Choi MH, Park Y. Retrospective analysis on the diagnostic performances and signal-to-cut-off ratios of the Elecsys Anti-HCV II assay. J Clin Lab Anal. 2018 Jan;32(1):e22165. doi: 10.1002/jcla.22165. Epub 2017 Feb 10. PMID: 28187227; PMCID: PMC6817162.

5. Alter MJ, Kuhnert WL, Finelli L; Centers for Disease Control and Prevention. Guidelines for laboratory testing and result reporting of antibody to hepatitis C virus. Centers for Disease Control and Prevention. MMWR Recomm Rep. 2003 Feb 7;52(RR-3):1-13, 15; quiz CE1-4. PMID: 12585742.

6. Contreras AM, Ochoa-Jimenez RJ, Celis A, Mendez C, Olivares L, Rebolledo CE, et al. High antibody level: an accurate serologic marker of viremia in asymptomatic people with hepatitis $\mathrm{C}$ infection. Transfusion. 2010 Jun;50(6):1335-43. doi: 10.1111/j.1537-2995.2009.02571.x. Epub 2010 Jan 15. PMID: 20088833.

7. Centers for Disease Control and Prevention (CDC). Testing for HCV infection: an update of guidance for clinicians and laboratorians. MMWR Morb Mortal Wkly Rep. 2013 May 10;62(18):362-5. PMID: 23657112; PMCID: PMC4605020.

8. NHS Executive. 5.4- Fatura, incelemeye esas belgelerin teslimi ve odeme işlemleri title of subordinate document. Sosyal Guvenlik Kurumu Saglık Uygulama Tebliginde Degisiklik Yapılmasına Dair Teblig. Ankara: Department of Health; 2018.

9. Kuhnert WL. Department of Health and Human Services. 2007. [cites 2019 Jul 04]. Available from:https://www.cdc.gov/hepatitis/hcv/pdfs/architectletter_5-24-0\%.pdf .

10. Ecemiş T, Akçalı S, Dündar PE, Şanlıdağ T. The Threshold Value of Anti-HCV Test in the Diagnosis of HCV Infection. Turkiye Klinikleri J Med Sci. 2012;32(6):1648-52.

11. Saygan MB. Transfuzyonla Bulasian Enfeksiyon Verileri (Turk Kizilayi 2015-2018). In: Uluhan R, Emekdas G, Heper Y,Bayik M, editors.XII. National Blood Centers and Transfusion Medical Congress Book; 2019 March 10-14; Antalya, Turkey. Istanbul: 2019. p. 65-81.

12. Şanlıdă̆ T, Akçalı S, Ecemiş T, Süer K, Erbay Dündar P, Arıkan A, et al. Investigation of the correlation between anti-HCV levels (S/Co) with HCV-RNA in the diagnosis of hepatitis $\mathrm{C}$ virus (HCV) infection. Mikrobiyol Bul. 2016 Jul;50(3):508-10. doi: 10.5578/mb.26509. PMID: 27525408.

13. Wu S, Liu Y, Cheng L, Yin B, Peng J, Sun Z. Clinical evaluation of the signal-to-cutoff ratios of hepatitis C virus antibody screening tests used in China. J Med Virol. 2011 Nov;83(11):1930-7. doi: 10.1002/jmv.22168. PMID: 21915868.

14. Seo YS, Jung ES, Kim JH, Jung YK, Kim JH, An H, et al. Significance of anti-HCV signalto-cutoff ratio in predicting hepatitis C viremia. Korean J Intern Med. 2009 Dec;24(4):302-8. doi: 10.3904/kjim.2009.24.4.302. Epub 2009 Nov 27. PMID: 19949727; PMCID: PMC2784972. 
15. Fletcher GJ, Raghavendran A, Sivakumar J, Samuel P, Abraham P. Diagnostic reliability of Architect anti-HCV assay: Experience of a tertiary care hospital in India. J Clin Lab Anal. 2018 Feb;32(2):e22245. doi: 10.1002/jcla.22245. Epub 2017 Jun 28. PMID: 28657153; PMCID: PMC6816955.

16. Granados-García V, Contreras AM, García-Peña C, Salinas-Escudero G, Thein HH, Flores YN. CostEffectiveness Analysis of Different Testing Strategies that Use Antibody Levels to Detect Chronic Hepatitis C in Blood Donors. PLoS One. 2016 May 9;11(5):e0154625. doi: 10.1371/journal.pone.0154625. PMID: 27159320; PMCID: PMC4861301.Table 1. Diagnostic accuracy for Anti HCV [?] 8.58 S/Co and Anti HCV [?]5.00 S/Co

\begin{tabular}{lllllll}
\hline Anti HCV & TP & P & TN & N & Sensitivity (95\%CI) & Specificity (95\%CI) \\
\hline [?]8.58 S/Co & 80 & 84 & 148 & 173 & $0.9524(0.876-0.985)$ & $0.8555(0.792-0.903) ?>?$ \\
$5.00 \mathrm{~S} / \mathrm{Co}$ & 83 & 84 & 127 & 173 & $0.9881(0.926-0.999)$ & $0.7341(0.661-0.797)$ \\
\hline
\end{tabular}

TP: Test Positive, P: Positive, TN: Test Negative, N: Negative.

Table 2a Costanalysis +

\begin{tabular}{lllllll}
\hline Anti-HCV Cutoff & True positive & Total positive & Cost for Unit (USD) & Total cost (USD) & Average cost (USD) & Marg \\
\hline [?]1.00 S/Co & 84 & 257 & 27.07 & 6956.99 & 82.82 & 1028. \\
$5.00 \mathrm{~S} / \mathrm{Co}$ & 83 & 129 & 27.07 & 3492.03 & 42.07 & 216.5 \\
$8.58 \mathrm{~S} / \mathrm{Co}$ & 80 & 105 & 27.07 & 2842.35 & 35.53 & 0 \\
\hline
\end{tabular}

+: Cost estimation based on provider perspective

++ : The cost for unit; the cost per HCV-RNA test was 27.07 USD.

Table 2b Workload analysis

\begin{tabular}{lllllll}
\hline Anti-HCV & True positive & Total positive & Workload unit (hours)§ & Total cost (hours) & Average workload (hours) & 1 \\
\hline [?]1.00 S/Co & 84 & 257 & 6.25 & 1606.25 & 19.12 & 2 \\
$5.00 \mathrm{~S} / \mathrm{Co}$ & 83 & 129 & 6.25 & 806.25 & 9.71 & 5 \\
$8.58 \mathrm{~S} / \mathrm{Co}$ & 80 & 105 & 6.25 & 656.25 & 8.20 & 0 \\
\hline
\end{tabular}

$\S$ : The workload unit; the workload per HCV-RNA test was 6.25 hours.

\section{Figure Legends}

Figure 1 Hepatitis $\mathrm{C}$ virus infection diagnosis algorithm and distribution of patients

Figure 2 ROC analysis of anti-HCV S/Co values according to HCV-RNA results. AUC-ROC was 0.942 for S/Co value of 8.58 (\%95CI:0.913-0.971) 


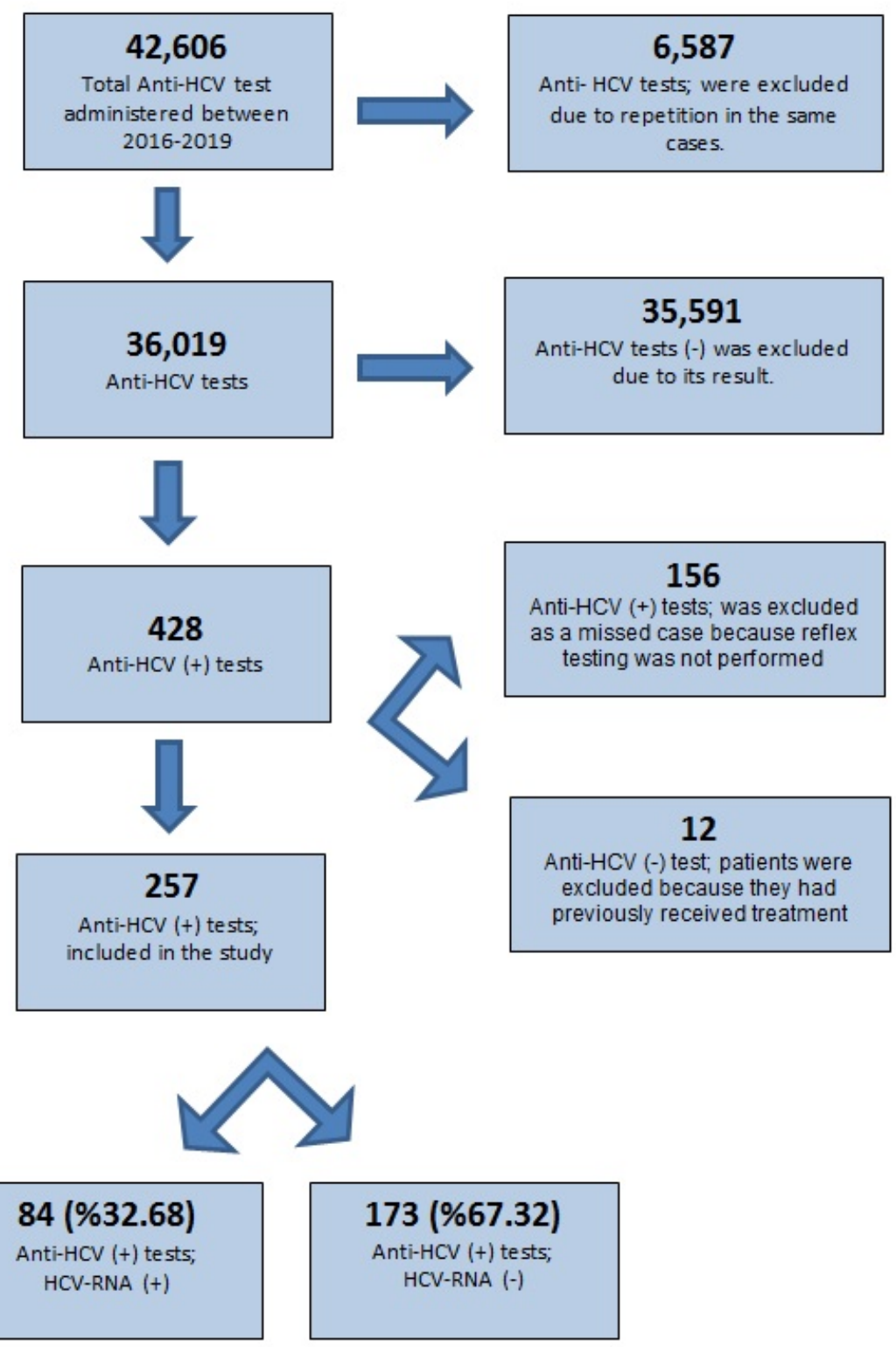




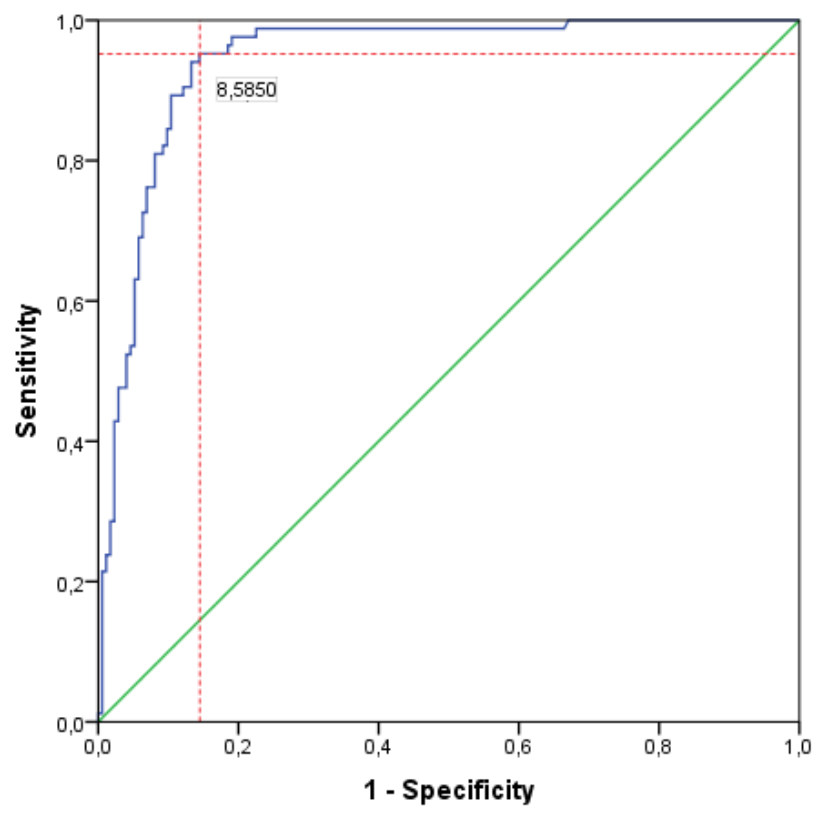

